\title{
Economic Evaluation of Area-based Forest Plans - A case study for the Tokyo University Forest in Chiba Prefecture-
}

\author{
Tomoko Takahashi*1,*2, Satoshi Tatsuhara*1, Yuejun Zheng ${ }^{* 1, * 3}$ and \\ Hidejiro Nagumo*1,*4
}

\begin{abstract}
This paper reports on the economic evaluation of simulated harvests resulting from various forest management plans. First, a series of procedures for the economic evaluation of forest management on the basis of sustainable forest plans were developed. The plans evaluated consist of a long-term plan, in which approximately equal areas would be cut during each working period, and medium-term plan, in which approximately equal amounts of labour would be involved each year. Costs, gross income, and net income of forest management are evaluated according to these plans. Next, Compartments 25 to 28 in the Tokyo University Forest in Chiba Prefecture were used as study areas, and they were assumed to be a working unit. The forest plans were made by using a geographic information system for sugi (Cryptomeria japonica) and hinoki (Chamaecyparis obtusa) plantations with 60-, 70- and 80-year rotations. Costs, gross income and net income for the plans were evaluated under nine sets of conditions of cost and timber price. Under the present conditions, net incomes per hectare were 1,176 thousand yen for the 60- and 70-year rotations and 852 thousand yen for the 80 -year rotation. The investment in the study site was profitable even under the worst set of conditions, even though the internal rate of return for a coniferous plantation is low. Therefore, if Japanese foresters have sufficient growing stock and forest roads, they can derive high profits from forest management.
\end{abstract}

Keyword: geographic information system, investment evaluation, simulation, sustainable forest plan

\section{INTRODUCTION}

Both sustainability and economics have to be taken into consideration to manage forests. In general, forest plans are made to maintain sustainability of forest

${ }^{*}$ Faculty of Agriculture, the University of Tokyo, 1-1-1 Yayoi, Bunkyo-ku, Tokyo 113 Japan

${ }^{*}$ Present address: Mitsui-Shin Information System Co., Ltd., 6-1-21 Shimomeguro, Meguroku, Tokyo 153 Japan

${ }^{* 3}$ Present address: The Institute of Statistical Mathematics, 4-6-7 Minamiazabu, Minato-ku, Tokyo 106 Japan

${ }^{* 4}$ Present address: College of Agriculture and Veterinary Medicine, Nihon University, 1866 Kameino, Fujisawa, Kanagawa 252 Japan resources. NAGUMO et al. (1993b) propounded three types of forest management plans: long-term plans, mediumterm plans and short-term plans. Long-term plans deal with assigning subcompartments to each working period over a rotation. Medium-term plans are annual plans, and they are made so that labour available will be assigned equally to each year. Short-term plans are operational schedules extending over a year. These types of plan have been developed as computer systems by NAGUMo et al. (1993a, 1993b) and ZHENG et al. (1995). However, they do not take economics into consideration.

The forest planning computer systems derived above have been developed on the basis of a geographic information system (GIS) for the Tokyo University Forest in Chiba Prefecture (hereafter called the "Chiba Forest") as a study site. Economic evaluation of forest management in Japan had already been studied for a stand by KuMAZAKI 
(1989) and IEHara (1993a, 1993b). It is also useful, however, to analyze forest plans economically by their simulation under various conditions for forest management. Therefore, this paper reports on the development of a computer system to evaluate forest plans made with GIS data. A relational database management system, dBASEIV, was utilized to develop the computer system. Sugi (Cryptomeria japonica D.DoN) and hinoki (Chamaecyparis obtusa (SIEB. et ZuCC.) ENDLICHER) plantations in the Chiba Forest were studied in this research.

\section{METHOD}

A flow chart of the procedures is shown in Fig. 1. The evaluation procedures are divided into three main parts: evaluation of cost, of gross income evaluation and of net income evaluation. Before the procedures are implemented, two kinds of forest plans should be made: long-term and medium-term. The medium-term plan is evaluated from an economic standpoint.

Long-term plan

The long-term plan is made by the area-period method ("Flähenfachwerksmethode") with the computer system developed by NAGUMO et al.(1993a). If a user specifies the beginning fiscal year, length of rotation, length of working period and tolerance limit of variation in the area, the system retrieves stand data from the database, reads yield tables, and makes a plan so that approximately equal areas and volumes will be contained in each working period under the specified conditions.

At the outset, the average cutting area per working period is calculated by means of total area and number of working periods. Then, each subcompartment is assigned to a certain period so that each cutting area will satisfy the following restriction:

$$
\left|\frac{A_{i}-A}{A}\right| \leqq t_{A}
$$

where $A_{i}$ is cutting area in the $i$-th period, $A$ is the average cutting area per period and $t_{A}$ is the tolerance limit. The volume of each stand to be cut is estimated from yield tables. Finally, the yield in each working period is estimated.

\section{Medium-term plan}

The medium-term plan is made with the computer system developed by NAGUMO et al.(1993b) so that each fiscal year will involve approximately equal amounts of labour. First, the fiscal year of each stand to be cut in the first period is specified, as are length of working period and tolerance limit of labour amount. Then, the system calcu-

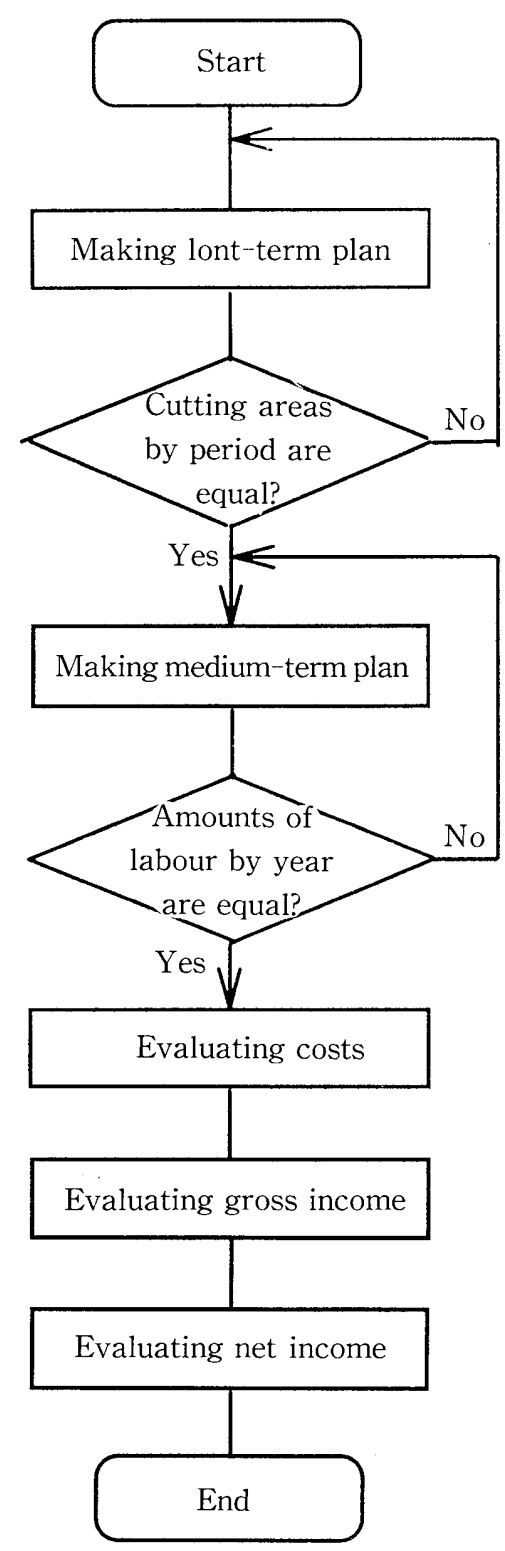

Fig. 1 The evaluation procedures

lates the amount of labour needed for each operation according to the tending system established for the Chiba Forest, as shown in Table 1. Each amount of labour is estimated from a standard labour table, modified by slope and distance from the road. That is to say, the actual amount is estimated from the standard amount multiplied by two coefficients developed by ZHENG et al. (1995):

Amount of labour $=$ Standard amount of labour $\times$ (distance coefficient + slope coefficient -1 ).

Distance coefficient $D I$ is determined as follows:

$$
D I=0.95858+0.01523 S+0.00008 D,
$$

where $D$ is distance from the road $(\mathrm{m}), S$ is slope class (1 to 4 ) and slope coefficient is determined as in Table 2 . The 
Table 1 Tending system in the Chiba Forest

\begin{tabular}{|c|c|}
\hline year & operation \\
\hline 1 & $\begin{array}{l}\text { Area measurement } \\
\text { Land perpatation } \\
\text { Transporting seedlings } \\
\text { Dividing stand } \\
\text { Planting } \\
\text { Measuring growth } \\
\text { Releasing }\end{array}$ \\
\hline 2 & $\begin{array}{l}\text { Supplementary planting } \\
\text { Releasing } \\
\text { Measuring growth }\end{array}$ \\
\hline 3 & $\begin{array}{l}\text { Releasing } \\
\text { Measuring growth }\end{array}$ \\
\hline 4 & $\begin{array}{l}\text { Releasing } \\
\text { Measuring growth }\end{array}$ \\
\hline 5 & $\begin{array}{l}\text { Releasing } \\
\text { Measuring growth }\end{array}$ \\
\hline 6 & Releasing \\
\hline 7 & Cutting vines \\
\hline $8-10$ & Waste thinning \\
\hline $9-11$ & Pruning \\
\hline $14-15$ & Waste thinning \\
\hline $14-15$ & Pruning \\
\hline $20-25$ & Thinning \\
\hline $30-35$ & Thinning \\
\hline 60 and over & Final cutting \\
\hline
\end{tabular}

Table 2 Slope coefficient by slope class

\begin{tabular}{ccc}
\hline Slope class & Slope (degrees) & Slope coefficient \\
\hline 1 & $0-15$ & 1.0 \\
2 & $16-25$ & 1.1 \\
3 & $26-35$ & 1.2 \\
4 & 36 and over & 1.3 \\
\hline
\end{tabular}

total amount of labour for the first period is calculated, and the average amount of labour is determined from the total amount and the length of the working period. Finally, the plan is checked to verify that amount of labour for each year satisfies the following restriction:

$$
\left|\frac{L_{i}-L}{L}\right| \leqq t_{L}
$$

where $L_{i}$ is amount of labour for the $i$-th fiscal year, $L$ is the average amount of labour per year and $t_{L}$ is the tolerance limit. If the amount of labour does not satisfy the restriction, the system modifies the years of thinning and pruning. If the amount of labour still does not satisfy the restriction after the modification, the user must change the harvesting schedule or the tolerance limit.

Evaluating costs

Foresters must pay such costs as planting, vegetation control and harvesting when they manage forests. The various costs of forest management can be sorted into four parts: personnel costs, working costs and construction costs for final felling and seedling costs. Personnel costs are expressed as follows:

Personnel costs (yen) = Amount of labour (persons . days) $\times$ daily wages $($ yen/person/day).

Working costs are those for logging and is calculated as follows:

Working costs (yen) = Unit working cost (yen/ $\left.\mathrm{m}^{3}\right) \times$ volume to be cut $\left(\mathrm{m}^{3}\right)$.

Construction costs are those for constructing facilities for $\log$ transportation, such as ropeways etc. Because the distance from the road to the working stand has little effect on the construction costs, such costs are assumed to be independent of the distance. Thus these cost are calculated as follows:

Construction costs (yen) = Unit construction cost $(\mathrm{yen} / \mathrm{ha}) \times$ area to be cut (ha) .

Seedling costs are fixed at the following:

$210,000 \mathrm{yen} / \mathrm{ha}$ for sugi (A seedling costs 70 yen, and 3,000 seedlings are planted per ha),

$280,000 \mathrm{yen} / \mathrm{ha}$ for hinoki (A seedling costs $80 \mathrm{yen}$, and 3,500 seedlings are planted per ha), because these costs are much less than the others.

Personnel costs occur every year, and they are calculated for each fiscal year: specified daily wages are multiplied by the amount of labour calculated by the mediumterm plan. Working costs apply only in fiscal years when final felling is carried out; they are calculated for each final felling year: unit working costs are multiplied by volume to be cut. Construction costs apply only in the fiscal years when working costs also apply; they are calculated for each final felling year: unit construction costs are multiplied by area to be cut. Seedling costs apply only in fiscal years when planting is carried out. In the medium-term plan, cut stands should be planted the next year after cutting. Seedling costs are calculated for each planting year: seedling costs are multiplied by areas to be planted. Total costs for each fiscal year are determined by adding the four costs of forest management.

Evaluating gross income

In this procedure, it is assumed that income from forest management derives from final felling only. First, tree prices per unit volume in 50-year-old sugi and hinoki plantations are specified. Next, ratios of unit tree prices to 
the unit tree price in 50-year-old plantations are determined and stored for $60^{-}$to 120 -year-old plantations of each species at 10-year intervals and then each unit tree price is calculated: each ratio is multiplied by specified unit tree price in 50-year-old plantations because these ratios generally do not vary(Fukushima, 1976, 1977). Finally, gross income for each fiscal year is calculated as follows:

Final felling income $(y e n)=$ cutting volume $\left(\mathrm{m}^{3}\right) \times$ unit tree price $\left(\mathrm{yen} / \mathrm{m}^{3}\right)$.

If a stand age does not exist among the ages used for the stored ratios, unit tree price for the stand age is obtained from the two nearest existing unit tree prices. For example, unit tree price for $84^{-}$year-old plantations is calculated as follows:

Price for 84-year-old stands $=$ Price for 80 -year-old stands + \{Price for 90 -year-old stands - Price for 80 -year-old stands $\} / 10 \times 4$.

Evaluating net income

Net income for the first working period is obtained from the costs and the gross income. First, net income for each fiscal year is calculated: then total costs are subtracted from final felling income. Thus, net income will be negative in every fiscal year during which final felling does not occur. Next, net income for the $n$-th fiscal year is discounted into net present value as follows:

$$
N=V /(1+p / 100)^{n}=V / 1.0 p^{n} \text {, }
$$

where $N$ is net present value at the beginning of the period, $V$ is net income for the $n$-th fiscal year of the period and $p$ is discount rate. Finally, net present value of the net income is obtained for the first period by totaling net present value for each fiscal year.

\section{APPLICATION}

The study site is Compartments 25 to 28 , in the Tokyo University's Chiba Forest. These compartments were assumed to be a working unit for simulation of the procedures outlined above. Fig. 2 depicts the study area with sugi and hinoki plantations. The area of coniferous plantations in the study site is $79.83 \mathrm{ha}$. Age-class distributions are shown in Table 3 . Of the total coniferous plantations on the site, $40 \%$ are 60 -year-old or older; the site already contains a large amount of growing stock. A stand table and forest map of the study area have been stored and linked together on the GIS by TATSUHARA et al. (1993, 1994).

\section{Establishing plans}

Rotations were set at 60,70 and 80 years and length of the working period was set at 10 years. The minimum of

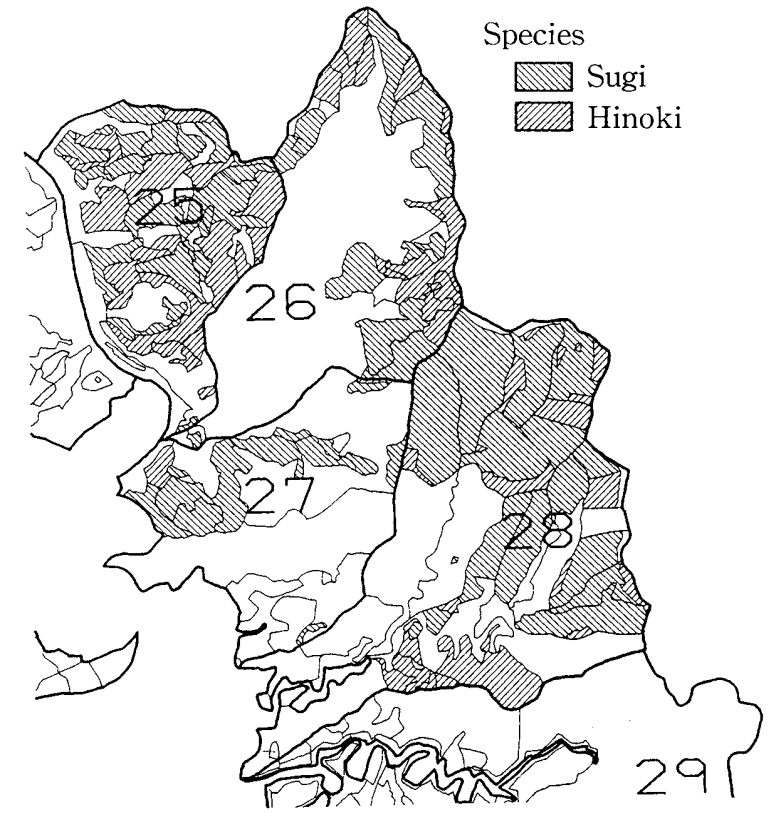

Fig. 2 Study area.

Note: Thick lines and thin lines show compartment and subcompartment boundaries, respectively. Numbers are compartment codes

Table 3 Age-class distribution of the study site

\begin{tabular}{crc}
\hline Age class & Age (yrs.) & Area (ha) \\
\hline 1 & $1-10$ & 2.60 \\
2 & $11-20$ & 8.01 \\
3 & $21-30$ & 10.85 \\
4 & $31-40$ & 13.29 \\
5 & $41-50$ & 3.96 \\
6 & $51-60$ & 6.24 \\
7 & $61-70$ & 0.42 \\
8 & $71-80$ & 17.08 \\
9 & $81-90$ & 11.22 \\
10 & $91-100$ & 0.00 \\
11 & $101-110$ & 6.16 \\
12 & $111-120$ & 0.00 \\
\hline
\end{tabular}

the area tolerance limit was obtained for each long-term plan by carrying out the procedure outlined above. These values were $0.07,0.05$ and 0.07 for $60^{-}, 70^{-}$and 80 -yearrotation plans, respectively. Table 4 shows the resulting cutting volumes for these simulations.

After the long-term planning, the amount of labour needed according to the medium-term plans were calculated (Table 5). Because the same stands will be cut in the first working period in the long-term plans for $60^{-}$and 70 -year rotations, these two long-term plans had the same medium-term plan. Therefore the table shows only two 
Table 4 Simulated cutting volumes for the long-term planning

(a) 60-year-rotation plan

\begin{tabular}{ccc}
\hline Working period & Cutting area (ha) & Cutting volume $\left(\mathrm{m}^{3}\right)$ \\
\hline 1 & 9.00 & $9,076.7$ \\
2 & 13.91 & $9,985.8$ \\
3 & 14.23 & $8,386.5$ \\
4 & 14.23 & $9,910.8$ \\
5 & 14.23 & $8,270.6$ \\
6 & 14.23 & $6,415.4$ \\
\hline Total & 79.83 & $52,345.8$ \\
\hline
\end{tabular}

(b) 70-year-rotation plan

\begin{tabular}{crc}
\hline Working period & Cutting area (ha) & Cutting volume $\left(\mathrm{m}^{3}\right)$ \\
\hline 1 & 9.00 & $9,076.7$ \\
2 & 11.05 & $8,409.8$ \\
3 & 11.92 & $6,560.9$ \\
4 & 11.97 & $8,880.2$ \\
5 & 11.97 & $7,940.4$ \\
6 & 11.96 & $8,200.7$ \\
7 & 11.96 & $5,203.7$ \\
\hline Total & 79.83 & $54,272.4$ \\
\hline
\end{tabular}

(c) 80-year-rotation plan

\begin{tabular}{crc}
\hline Working period & Cutting area (ha) & Cutting volume $\left(\mathrm{m}^{3}\right)$ \\
\hline 1 & 0.00 & $6,420.0$ \\
2 & 6.03 & $8,028.3$ \\
3 & 10.02 & $6,902.1$ \\
4 & 10.56 & $6,991.4$ \\
5 & 10.62 & $8,403.0$ \\
6 & 10.64 & $7,188.9$ \\
7 & 10.65 & $7,337.1$ \\
8 & 10.66 & $5,224.8$ \\
\hline Total & 79.83 & $56,495.6$ \\
\hline
\end{tabular}

plans: the first is for $60^{-}$and 70 -year rotations and the second is for an 80 -year rotation. The minimums of tolerance limits of labour were $34 \%$ and $16 \%$ for $60^{-}$and $80^{-}$ year rotations, respectively.

Economic evaluation

Management of the study site was evaluated on the basis of the medium-term plan discussed above. Conditions were specified as follows:

Daily wages $=8,000$ yen,

Unit working cost $=10,000$ yen $/$ ha,

Unit construction cost $=20,000,000$ yen $/$ ha,

Price of sugi trees in a 50-year-old stand $=17,400$ yen $/ \mathrm{m}^{3}$,

Price of hinoki trees in a 50-year-old stand $=37,000$ yen $/ \mathrm{m}^{3}$,

Discount rate $=3 \%$.

Furthermore, the conditions were changed: it was assumed that all costs would increase or decrease by $10 \%$ and that prices would also increase or decrease by $10 \%$. Table 6 shows the results of the simulation under the nine sets of conditions outlined above. Each value is the net present value of net income for each plan; net present value of net income per hectare is also shown in parentheses. Net incomes per hectare were 1,176 thousand yen and 852 thousand yen for the $60^{-}$and 80 -year-rotation plans, respectively.

\section{DISCUSSION}

The results of the simulation show that investment in management of the site for the first working period (that is, one decade from now) is very profitable and it continues to be so even under the worst set of conditions in the simulation. Net income for the 60 -year-rotation plan was larger than that for the 80 -year-rotation plan. It does not follow, however, that a rotation of 60 years is more profitable than a rotation of 80 years, because this simulation evaluates management not of a stand but of the total working unit and not for the whole rotation but for a period. Thus, the results of this simulation depend not only on management costs and timber price but also on ageclass distribution of the site and rotation. Because the study site contains large area of stands older than 80 years as Table 1 and more stands will be harvested for each period in the 60-year-rotation plan than in the 80-year-rotation plan, more gain from old stands will be derived for the first period in the 60-year-rotation plan than in the 80-yearrotation plan. Indeed, KuMAZAKI (1989) and IEHARA (1993 b) pointed out that long-rotations (that is 80 to 100 years) are more profitable than the present standard rotations (that is 45 to 50 years) for sugi and hinoki.

The present evaluation was made to cover specified periods on the basis of area-based forest plans. Generally, however, it is said that investments in forest management yield a bad return in Japan. For example, the JAPANESE FORESTRY AGENCY (1994) stated that an average rate of return for investment in sugi plantations was $0.9 \%$ in 1993. In our case, the internal rate of return for sugi plantation was $0.6 \%$ for a 60 -year rotation and $0.9 \%$ for an 80 -year rotation. Nevertheless, the investment in the study site yielded a good return even under the worst set of conditions. Therefore, if foresters have sufficient growing stock and forest roads, they can derive good gains from forest management under the specified plans and rotations, even though the internal rate of return is low. 
Table 5 Amount of labour needed for each kind of work according to the medium-term plans (a) 60-and-70 year-rotation plans

\begin{tabular}{lrrrrrrrrrrr}
\hline & \multicolumn{10}{c}{ Labour needed (persons • days) } \\
\cline { 2 - 11 } Kind of work & 1995 & 1996 & 1997 & 1998 & 1999 & 2000 & 2001 & 2002 & 2003 & 2004 & Total \\
\hline Final felling & 17.4 & 0.0 & 13.1 & 0.0 & 41.5 & 0.0 & 22.4 & 0.0 & 22.4 & 0.0 & 116.8 \\
Area measurement & 0.0 & 3.0 & 0.0 & 2.0 & 0.0 & 7.0 & 0.0 & 4.0 & 0.0 & 4.0 & 20.0 \\
Land preparation & 0.0 & 62.0 & 0.0 & 46.5 & 0.0 & 147.6 & 0.0 & 79.5 & 0.0 & 79.5 & 415.1 \\
Transporting seedlings & 0.0 & 4.4 & 0.0 & 3.3 & 0.0 & 10.5 & 0.0 & 5.6 & 0.0 & 5.6 & 29.4 \\
Dividing stand & 0.0 & 7.3 & 0.0 & 5.5 & 0.0 & 17.4 & 0.0 & 9.4 & 0.0 & 9.4 & 49.0 \\
Planting & 0.0 & 60.1 & 0.0 & 45.1 & 0.0 & 143.1 & 0.0 & 77.1 & 0.0 & 77.1 & 402.5 \\
Measuring growth & 0.0 & 6.4 & 3.2 & 8.0 & 5.6 & 21.0 & 10.1 & 18.4 & 11.8 & 20.1 & 104.6 \\
Releasing & 0.0 & 15.7 & 31.4 & 43.2 & 54.9 & 76.5 & 113.9 & 106.6 & 126.7 & 97.6 & 666.5 \\
Supplementary planting & 0.0 & 0.0 & 8.2 & 0.0 & 6.2 & 0.0 & 19.5 & 0.0 & 10.5 & 0.0 & 44.4 \\
Cutting vine & 0.0 & 0.0 & 0.0 & 0.0 & 0.0 & 0.0 & 0.0 & 5.6 & 0.0 & 4.2 & 9.8 \\
Waste thinning & 156.6 & 76.5 & 0.0 & 93.0 & 0.0 & 0.0 & 0.0 & 0.0 & 40.3 & 0.0 & 366.4 \\
Pruning & 101.3 & 0.0 & 227.8 & 0.0 & 246.4 & 0.0 & 0.0 & 0.0 & 0.0 & 0.0 & 575.5 \\
Thinning & 38.5 & 72.4 & 25.7 & 58.6 & 0.0 & 0.0 & 108.9 & 0.0 & 62.5 & 0.0 & 366.6 \\
\hline Total & 318.8 & 307.7 & 309.4 & 305.4 & 354.6 & 423.1 & 274.8 & 306.0 & 274.2 & 297.3 & 3166.3 \\
\hline
\end{tabular}

(b) 80-year-rotation plan

\begin{tabular}{lrrrrrrrrrrr}
\hline & \multicolumn{10}{c}{ Labour needed (persons days) } \\
\cline { 2 - 11 } Kind of work & 1995 & 1996 & 1997 & 1998 & 1999 & 2000 & 2001 & 2002 & 2003 & 2004 & Total \\
\hline Final felling & 0.0 & 17.4 & 0.0 & 13.1 & 0.0 & 22.4 & 0.0 & 22.4 & 0.0 & 0.0 & 75.3 \\
Area measurement & 0.0 & 0.0 & 3.0 & 0.0 & 2.0 & 0.0 & 4.0 & 0.0 & 4.0 & 0.0 & 13.0 \\
Land preparation & 0.0 & 0.0 & 62.0 & 0.0 & 46.5 & 0.0 & 79.5 & 0.0 & 79.5 & 0.0 & 267.5 \\
Transporting seedlings & 0.0 & 0.0 & 4.4 & 0.0 & 3.3 & 0.0 & 5.6 & 0.0 & 5.6 & 0.0 & 18.9 \\
Dividing stand & 0.0 & 0.0 & 7.3 & 0.0 & 5.5 & 0.0 & 9.4 & 0.0 & 9.4 & 0.0 & 31.6 \\
Planting & 0.0 & 0.0 & 60.1 & 0.0 & 45.1 & 0.0 & 77.1 & 0.0 & 77.1 & 0.0 & 259.4 \\
Measuring growth & 0.0 & 0.0 & 6.4 & 3.2 & 8.0 & 5.6 & 13.9 & 6.5 & 14.8 & 8.2 & 66.6 \\
Releasing & 0.0 & 0.0 & 15.7 & 31.4 & 43.2 & 54.9 & 59.3 & 79.4 & 72.1 & 92.2 & 448.2 \\
Supplementary planting & 0.0 & 0.0 & 0.0 & 8.2 & 0.0 & 6.2 & 0.0 & 10.5 & 0.0 & 10.5 & 35.4 \\
Cutting vine & 0.0 & 0.0 & 0.0 & 0.0 & 0.0 & 0.0 & 0.0 & 0.0 & 5.6 & 0.0 & 5.6 \\
Waste thinning & 99.3 & 57.3 & 76.5 & 93.0 & 0.0 & 0.0 & 0.0 & 0.0 & 0.0 & 40.3 & 366.4 \\
Pruning & 101.3 & 144.5 & 0.0 & 83.3 & 111.2 & 135.2 & 0.0 & 0.0 & 0.0 & 0.0 & 575.5 \\
Thinning & 38.5 & 16.5 & 55.9 & 25.7 & 0.0 & 58.6 & 0.0 & 108.9 & 0.0 & 62.5 & 366.6 \\
\hline Total & 239.1 & 235.7 & 291.2 & 257.9 & 265.0 & 282.9 & 248.6 & 227.7 & 267.9 & 213.7 & 2529.7 \\
\hline
\end{tabular}

\section{CONCLUSION}

Procedures were developed for the economic evaluation of forest management on the basis of sustainable forest plans made with GIS. Long- and medium-term plans were integrated with the evaluation of costs and income. The procedures are useful for evaluating a forest plan under specified conditions of timber price and management costs and comparing various forest plans before one is implemented.

The procedures still need to be improved. If a site without sufficient forest roads is to be evaluated, the cost of constructing such roads must be considered and the amount of labour needed for their construction must be included in the medium-term plan. Moreover, income from thinning was not taken into consideration in the procedures. For old stands, however, thinning is generally profitable even in Japan. Thus, income from thinning should be considered for plans established for very long rotation.

\section{ACKNOWLEDGMENTS}

The authors thank the staff members at the Chiba Forest for providing stand tables, forest maps as well as other information on forest management. 
Table 6 Results of economic evaluation of the study site (Unit, yen)

(a) 60-and 70-year-rotation plans

\begin{tabular}{lrrr}
\hline Timber & \multicolumn{3}{c}{ Cost } \\
\cline { 2 - 4 } price & $-10 \%$ & Present & $+10 \%$ \\
\hline$-10 \%$ & $84,378,685$ & $72,636,143$ & $60,893,604$ \\
& $(1,056,980)$ & $(909,885)$ & $(762,791)$ \\
Present & $105,587,223$ & $93,844,691$ & $82,012,152$ \\
& $(1,322,651)$ & $(1,175,557)$ & $(1,027,335)$ \\
$+10 \%$ & $127,085,524$ & $115,342,983$ & $103,600,443$ \\
& $(1,591,952)$ & $(1,444,858)$ & $(1,297,763)$ \\
\hline
\end{tabular}

Note: Values in parentheses are net present values per hectare.

(b) 80-year-rotation plan

\begin{tabular}{lrrr}
\hline Timber & \multicolumn{3}{c}{ Cost } \\
\cline { 2 - 4 } price & $-10 \%$ & Present & $+10 \%$ \\
\hline \multirow{2}{*}{$10 \%$} & $61,119,354$ & $52,663,948$ & $44,208,540$ \\
& $(765,618)$ & $(659,701)$ & $(553,783)$ \\
Present & $76,434,652$ & $67,979,244$ & $59,523,838$ \\
& $(957,467)$ & $(851,550)$ & $(745,632)$ \\
$+10 \%$ & $91,954,156$ & $83,498,749$ & $75,043,342$ \\
& $(1,151,875)$ & $(1,045,957)$ & $(940,039)$ \\
\hline
\end{tabular}

Note: Values in parentheses are net present values per hectare.

\section{LITERATURE CITED}

Fukushima, T., (1976): Quality and market price of log: a case for sugi (Cryptomeria japonica). Trans. Mtg. Kyushu Br. Jpn. For. Soc. 29: 5 -6 (in Japanese only)*

Fukushima, T., (1977): Quality and market price of log: a case for hinoki (Chamaecyparis obtusa). Trans. Mtg. Kyushu Br. Jpn. For. Soc. 30: 21-22 (in Japanese only) *

IEHARA, T., (1993a): A comparison of log volume and profit between an unthinned and a thinned Chamaecyparis obtusa stand. Jpn. J. For. Plann. 21: 17-33 (in Japanese with English summary) .

IEHARA, T., (1993b): A profitability and economic evaluation of the forest management of hinoki in a long-rotation operation. J. Jpn. For. Soc. 75: 34-40 (in Japanese with English summary)

JaPANESE Forestry AgEnCY, (1994): Forestry white paper of the 1994 fiscal year. Japan Forest Association, Tokyo, 302 pp (in Japanese only)*

KUMAZAKI, M., (1989): Forest management book. Japan Forest Investigation Committee, Tokyo, 237pp (in Japanese only)*

Nagumo, H., Zheng, Y., Tatsuhara, S. and Suzuki, M., (1993a): Constructing a yield regulation system using geographic information system. Trans. Mtg. Kanto Br. J. Jpn. For. Soc. 44: 41-42 (in Japanese only)

Nagumo, H., Zheng, Y., Tatsuhara, S. and Suzuki, M., (1993b): A study on forest management planning system using geographic information system (I) Medium-range plan. Trans. Mtg. J. Jpn. For. Soc. 104: 221-224 (in Japanese only)

Tatsuhara, S., Nagumo,H., Suzuki, M. and Saito, K., (1994): Geographical distribution of forest types in the Tokyo University Forest in Chiba. Bull. Tokyo Univ. For. 92: 135-143

Tatsuhara, S., Saito, K., Suzuki, M. and Nagumo, H., (1993): Preparation of forest information using geographic information system: a case study for the Tokyo University Forest in Chiba. Trans. Mtg. Jpn. For. Soc. 104: 275-276 (in Japanese only)

Zheng, Y., Nagumo, H. and Tatsuhara, S., (1995): A study on a forest management planning system: Short-term plan. J. Jpn. For. Soc. 17: 28-34 (in Japanese with English summary)

* The titles are tentative translations from original Japanese titles by the authors of this paper.

(Received 18 September 1995) (Accepted 4 December 1995) 